\title{
Habitat selection by a marine copepod during the productive season in the Subarctic
}

\author{
Sünnje L. Basedow ${ }^{1, *}$, Kurt S. Tande ${ }^{2}$, Leif Christian Stige ${ }^{3}$ \\ ${ }^{1}$ Department of Aquatic Biosciences, Faculty of Biosciences, Fisheries and Economics, University of Tromsø, \\ 9037 Tromsø, Norway \\ ${ }^{2}$ Faculty of Biosciences and Aquaculture, Bodø University College, 8049 Bodø, Norway \\ ${ }^{3}$ Centre for Ecological and Evolutionary Synthesis, Department of Biology, University of Oslo, PO Box 1066 Blindern, \\ 0316 Oslo, Norway
}

\begin{abstract}
Few studies have analysed the depth distribution of marine zooplankton at high-resolution, and knowledge obtained from theoretical modelling studies predominates over that from empirical field studies. We analysed depth selection by the marine copepod Calanus finmarchicus during spring and summer in neritic and oceanic Subarctic regions. Data on hydrography and zooplankton distribution in the upper $100 \mathrm{~m}$ were collected at high resolution by a towed instrument platform equipped with CTD, fluorometer and an optical plankton counter. Four extensive field data sets covering time windows from 3 to $11 \mathrm{~d}$ during the productive season were analysed using generalized additive mixed models. Our main findings were that: (1) mean depth of older development stages (CV and adults) of C. finmarchicus was best predicted by biotic factors (depth of the fluorescence maximum and population density), while abiotic factors (depth of the pycnocline) were of secondary importance, (2) depth selection was similar in neritic and oceanic areas, and (3) there was no evidence for synchronous diel vertical migration. Our results suggest that copepods dynamically and consistently select their habitat (depth) based on food conditions and predators in a densitydependent manner. We conclude that ecological interactions may drive habitat choice of planktonic organisms even in highly fluctuating oceanic environments.
\end{abstract}

KEY WORDS: Habitat choice $\cdot$ Depth selection $\cdot$ Optical plankton counter $\cdot$ Generalized additive mixed model $\cdot$ GAMM $\cdot$ Calanus $\cdot$ Density-dependence $\cdot$ Seasonality

\section{INTRODUCTION}

Habitat is most commonly defined as the spatial realisation of the ecological niche, i.e. of the conditions that are necessary for a population to live, reproduce and grow (e.g. Begon et al. 2006). On decadal time scales marine zooplankton are dispersed ocean-wide by currents, yet the geographical distribution of a zooplankton species is limited by physiological constraints and by competition (e.g. Fromentin \& Planque 1996). The geographical distribution can thus be viewed as the 2dimensional representation of the realised niche. Like the marine pelagic zone itself, the habitat of a marine zooplankton species is also inherently 3-dimensional. While 2 dimensions of the habitat of a marine zoo- plankton species are predetermined by ocean currents, individuals can respond behaviourally to cues along the vertical axis. Studies on habitat choice by marine zooplankton therefore address the selection of different depth strata with respect to abiotic and biotic factors.

Zooplankton in the Subarctic face an environment with strong seasonal fluctuations in growth conditions and predation pressure (Parsons \& Lalli 1988). The life cycle of many Subarctic zooplankton species has been moulded to match these seasonal fluctuations. The mainly herbivorous copepod Calanus finmarchicus, for example, exhibits seasonal ontogenetic vertical migrations spanning 100s to 1000s of metres (Conover 1988). It overwinters in a state of diapause in the deep basins 
of the North Atlantic while reproduction and growth take place in the food-rich epipelagic zone during spring and summer (Gislason et al. 2000, Heath et al. 2004, Edvardsen et al. 2006). In the epipelagic zone, copepods are subject to predation pressure by multiple invertebrate and vertebrate predators, which often feed size-specifically on certain developmental stages of their prey only (Dalpadado et al. 2000, Eiane et al. 2002). During development, copepods typically increase in size by an order of magnitude (Hirst \& Bunker 2003); they thus grow from the size-window of one set of predators into the next. In addition to changes in size-specific predation pressure, resource demands of copepod offspring increase with increasing size (Hirst \& Bunker 2003). Recently, nauplii and copepodites of several copepod species have been shown to segregate ontogenetically in the water column depending on predation risk and growth demands (Titelman \& Fiksen 2004, Basedow et al. 2008), suggesting that these factors drive ontogenetic changes in vertical behaviour.

Seasonal differences in vertical migration behaviour based on different assessments of predation risk and growth might also exist within similar-sized developmental stages. For Calanus spp., resource demands are highest in adult females of the reproducing $\mathrm{G}_{0}$ generation; CV copepodites of the new generation $\left(\mathrm{G}_{1}\right)$ have lower resource demands (Rey-Rassat et al. 2002). Furthermore, the $G_{0}$ generation usually dies off after reproduction, while late copepodite stages of the $\mathrm{G}_{1}$ generation prepare for overwintering by filling their lipid reserves during June to September (Kattner \& Krause 1987) and do not reproduce until the next year(s). Females of the $\mathrm{G}_{0}$ generation can directly maximise fitness by selecting a food-rich depth layer, because egg production of Calanus sp. is proportional to food intake (Niehoff et al. 1999), and because predation risk on adult copepods early in spring is relatively low (Kaartvedt 2000). In addition, females are broadcast spawners; the death of the female after spawning therefore does not imply the death of the offspring. Models have also indicated that it might be of adaptive significance for Calanus spp. to stay in the food-rich habitat and to produce eggs early in the season due to the increased fitness of these eggs (Fiksen \& Carlotti 1998, Varpe et al. 2009). Indeed, during the spring bloom, adult female Calanus spp. usually do not perform diel vertical migrations (DVM) and are found in the depth layer where primary production is at maximum (Tande \& Båmstedt 1985, Longhurst \& Harrison 1989, Durbin et al. 1995). CV copepodites of the $G_{1}$ generation have to balance the foraging time spent in the food-rich surface layer against increased predation pressure from tactile and visual predators in summer (Kaartvedt 2000, Dale et al. 2001). The only evolutionary stable strategy may therefore be to perform verti- cal migrations and so to alternate between food-rich surface layers and safer deeper layers (Pearre 2003). In Subarctic and Arctic areas where the productive period is short, however, it might be especially important to spend enough time in the food-rich layer. This might be one reason for the often observed absence of DVM in the Arctic (Fiksen 2000). Another reason might be that vertical migration behaviour of individuals in polar areas can be asynchronous, depending on the individuals' physiological state rather than on light (Pearre 2003). These asynchronous vertical migrations can mask DVM completely, such that it is not observed by traditional sampling (Cottier et al. 2006).

Field data that are collected on relevant scales to permit analysis of habitat selection by marine zooplankton are scarce, especially from Subarctic and Arctic areas and even more so from advective and from oceanic areas (but see Hays et al. 1996, Basedow et al. 2008, Fossheim \& Primicerio 2008). It is therefore no coincidence that most of our knowledge on habitat choice by zooplankton stems from limnetic areas and from modelling studies (Zaret \& Suffern 1976, Neill 1990, Hugie \& Dill 1994, Lampert et al. 2003, Primicerio 2003). There is therefore a need for new studies, utilising high-resolution biological and physical data combined, to evaluate empirically how habitat choice by copepods in different areas and seasons depend on environmental factors.

During the last decade, several field surveys during which physical and biological data were collected at high-resolution along the depth axis, were conducted in the Subarctic Norwegian and Barents Seas. The data cover a spring and early summer situation (MayJune) in northern marine habitats. The copepod population likely changed from the overwintering $\mathrm{G}_{0}$ generation to the recruiting $\mathrm{G}_{1}$ generation during these seasons (Halvorsen \& Tande 1994). Based on 4 of these unique data sets we analysed differences in habitat choice by the marine copepod Calanus finmarchicus during the productive season in the epipelagic zone. We focus on 3 questions in particular: (1) Which abiotic and biotic factors are related to habitat choice by the marine copepod Calanus finmarchicus? (2) Is there a difference in vertical distribution between neritic and oceanic areas? and (3) Do females and CV copepodites perform DVM during the productive period in the Subarctic?

\section{MATERIALS AND METHODS}

Data acquisition. The data used in this study were collected during 4 cruises carried out in the Norwegian Sea and the Barents Sea on the RV 'Johan Ruud' and RV 'Jan Mayen', respectively, from 2001 to 2003 (Fig. 1, Table 1). Data were collected by a towed sam- 


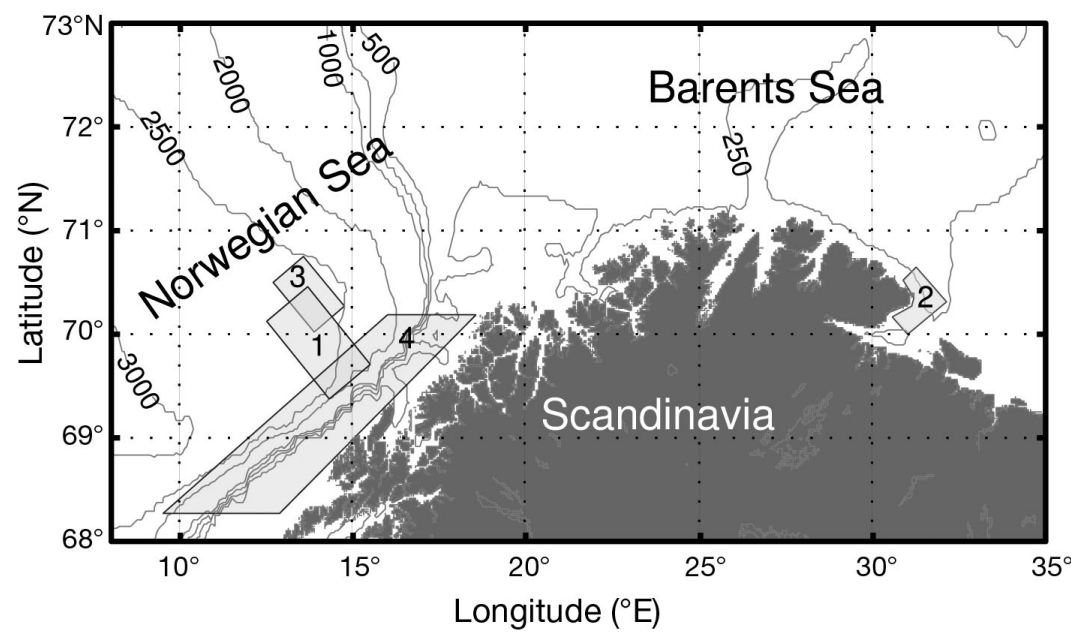

Fig. 1. Study areas. Four cruises were carried out in neritic $(2,4)$ and oceanic $(1,3)$ areas of the Barents and Norwegian Seas in spring $(1,2)$ and early summer $(3,4)$ 2001-2003. During Cruise 4 some oceanic areas were also sampled, but only data from the neritic parts were used in this study. See Table 1 for exact sampling times

pling platform (Scanfish, GMI) that was equipped with an optical plankton counter (OPC; Focal Technologies), a CTD (SBE 911, Seabird Electronics) and a fluorescence sensor ( $F$; Seapoint Chlorophyll Fluorometer, Seapoint Sensors). The Scanfish with the instrument package was towed along transects, undulating in the upper water column (Table 1). During the tows, OPC-CTD-F data were collected at a frequency of $2 \mathrm{~Hz}$. We thus obtained 4 large-scale data sets on hydrography and zooplankton distribution with highresolution in space and time. We sampled mostly down to $100 \mathrm{~m}$, because foraging copepods of the $\mathrm{G}_{1}$ generation are generally observed within the upper $100 \mathrm{~m}$ during the productive season (e.g. Longhurst \& Harrison 1989). In addition to the Scanfish sampling, information on zooplankton species composition was obtained from net hauls carried out either with a MOCNESS (180 $\mu \mathrm{m}$ mesh size, $0.25 \mathrm{~m}^{2}$ mouth opening; Wiebe et al. 1985) or with a WP2 (180 $\mu \mathrm{m}$ mesh size, $0.196 \mathrm{~m}^{2}$ mouth opening) at several stations during 3 of the 4 cruises (Table 1). Net tows were vertical stratified hauls from the upper $120 \mathrm{~m}$ (Cruise 2) or the upper $100 \mathrm{~m}$ (Cruises 1 \& 3). Net samples were preserved immediately in a solution of $80 \%$ seawater and $20 \%$ fixation agent $150 \%$ formalin buffered with hexamine, 50\% antibactericide propandiol).

Analysis of net samples. Ashore, zooplankton samples were split into subsamples containing at least 100 Calanus finmarchicus. From these sub-samples, organisms were identified under a stereomicroscope. Hydrozoans (diameter) and chaetognaths (length) were measured if they made up more than $1 \%$ of the total mesozooplankton abundance. Abundance was calculated based on filtered volume, which was either obtained directly from the MOCNESS or, for the WP2, computed from vertical hauling distance multiplied with the mouth area and assuming $100 \%$ filtration efficiency.

Analysis of OPC data. The OPC counts and measures particles while being towed through the water. Particles pass through the OPC sampling tunnel $(7 \times$ $7 \mathrm{~cm}$ opening) and cross a light beam. During passage, particles are enumerated and sized based on the amount of light they occlude (Herman 1992). Particle size is registered as digital size by the OPC, but equivalent spherical diameter (ESD) is commonly used to describe particle size in studies employing OPCs. Using a semi-empirical relationship (Herman 1992), we converted digital size into $\mathrm{ESD}$, i.e. the diameter of a sphere that has the same cross-sectional area as the measured particle.

Reliability of OPC data: Compared to net samples of zooplankton, the OPC yields data with a dramatically higher spatial resolution, but it does not yield taxonomic information and cannot distinguish between zooplankton and detrital particles. When towing the OPC at a speed of 7 knots, large phytoplankton aggregates and marine snow are most likely eroded and broken up into small particles due to turbulent flow

Table 1. Data collection during the 4 cruises. Number of transects sampled during each cruise with the Scanfish CTD-F-OPC instrument package and number of stations during which net hauls for zooplankton species composition were taken. During Cruise 4, the Scanfish undulated between 0 and $50 \mathrm{~m}$ or, if bottom depth was $<60 \mathrm{~m}$, from 0 to $10 \mathrm{~m}$ above the bottom. Cruise numbers refer to the locations depicted in Fig. 1

\begin{tabular}{|lcccccc|}
\hline Cruise & Date & Season & Habitat & Depth (m) & Transects & Number of stations \\
\hline 1 & 5-13 May 2003 & Spring & Oceanic & $0-60$ & 10 (ca. 100-150 km each) & 11 \\
2 & 17-27 May 2002 & Spring & Neritic & $0-100$ & 28 (ca. 30-40 km each) & 27 \\
3 & 6-8 June 2003 & Summer & Oceanic & $0-100$ & 4 (ca. 70 km each) & 2 \\
4 & 12-16 June 2001 & Summer & Neritic & $0-50$ & 4 (ca. 70 km each) & 0 \\
\hline
\end{tabular}


and associated shear stress at the opening of the OPC (Edvardsen et al. 2002). Counts of detritus in our study were therefore likely to influence particle counts at small sizes only, i.e. below $0.4 \mathrm{~mm}$ ESD at most. Coincidence counts are another issue that potentially influences the results obtained from the OPC. These occur when 2 particles enter the light beam simultaneously, they are then counted as one and hence particle size is over-estimated. Coincidence counts typically start to occur at very high plankton abundances, i.e. approximately above 7000 to 10000 ind. $\mathrm{m}^{-2}$ (Osgood

Table 2. Composition (in \% of total abundance) of the mesozooplankton community in the Norwegian and Barents Seas during 3 cruises in spring and summer 2002-2003 (see Table 1, Fig. 1), based on vertical net hauls. Shown are only taxa that contributed more than $1 \%$ to total mesozooplankton during at least one of the cruises. No net samples were available from the summer cruise in the neritic area (Cruise 4 ). $\mathrm{Sp}=$ spring, $\mathrm{Su}=$ summer, $\mathrm{O}=$ oceanic, $\mathrm{N}=$ neritic. - : absent, indet.: indeterminable

\begin{tabular}{|lcccc|}
\hline Taxon & Stage & $\begin{array}{c}\text { Cruise 1 } \\
(\mathrm{Sp}, \mathrm{O})\end{array}$ & $\begin{array}{c}\text { Cruise 2 } \\
(\mathrm{Sp}, \mathrm{N})\end{array}$ & $\begin{array}{c}\text { Cruise 3 } \\
(\mathrm{Su}, \mathrm{O})\end{array}$ \\
\hline Copepoda & Nauplii & 52.0 & 15.8 & 0.02 \\
Calanus finmarchicus & CI & 8.7 & 13.4 & 0.1 \\
& CII & 3.8 & 15.1 & 1.6 \\
& CIII & 3.0 & 12.4 & 4.4 \\
& CIV & 2.6 & 7.1 & 22.1 \\
& CV & 1.3 & 1.9 & 11.0 \\
& CVI o & 1.8 & 0.3 & 2.1 \\
C. hyperboreus & CVI o & - & 0.02 & - \\
Metridia spp. & CI-CVI & 3.1 & 0.06 & 0.1 \\
Pseudocalanus spp. & CI-CVI & 0.07 & 1.8 & 0.1 \\
Oithona spp. & CI-CVI & 4.0 & 0.4 & 7.8 \\
Triconia spp. & CI-CVI & 12.9 & 11.6 & 12.9 \\
Cirripedia & CI-CVI & 1.6 & 0.2 & - \\
Euphausiacea & Larvae & - & 4.3 & - \\
Hydrozoa & Calyptopis & 0.08 & 1.4 & 0.6 \\
Oikopleura spp. & Medusae & - & 0.01 & 23.2 \\
Chaetognatha & indet. & 3.2 & 6.7 & 6.4 \\
& indet. & 0.9 & 0.04 & 2.4 \\
\hline
\end{tabular}

Table 3. Size classification of zooplankton applied to the optical plankton counter data collected during 2001-2003 in neritic and oceanic areas of the Norwegian and Barents Seas. Size classification was based on literature data and on results from net samples. The most common organisms in each size class are listed; if organisms were common during some periods only, this is shown in parentheses. $\mathrm{Sp}=$ spring, $\mathrm{Su}=$ summer, $\mathrm{N}=$ neritic, $\mathrm{O}=$ oceanic

\begin{tabular}{|lcl|}
\hline Size class & ESD range $(\mathrm{mm})$ & \multicolumn{1}{c|}{ Main zooplankton group } \\
\hline $\mathrm{XS}$ & $0.25-0.6$ & $\begin{array}{l}\text { Calanoid nauplii (Sp), Cirripedia larvae } \\
\text { (Sp, N), Oithona spp., Pseudocalanus } \\
\text { spp. (O), Calanus finmarchicus CI (Sp), } \\
\text { detritus, Hydrozoa (Su, O) }\end{array}$ \\
$\mathrm{S}$ & $0.6-1.0$ & $\begin{array}{l}\text { C. finmarchicus CII-CIII, Hydrozoa (Su, O) } \\
\mathrm{M}\end{array}$ \\
$\mathrm{L}$ & $1.0-1.5$ & $\begin{array}{l}\text { C. finmarchicus CIV, Chaetognatha (O) } \\
\text { C. finmarchicus CV-CVI } 9\end{array}$ \\
$\mathrm{XL}$ & $1.5-2.0$ & \begin{tabular}{l} 
Oikopleura spp., larger invertebrate predators \\
\hline
\end{tabular}
\end{tabular}

\& Checkley 1997, Sprules et al. 1998). These high bundances are more typical for freshwater systems fluence our conclusions.

Size classification of $\boldsymbol{O P C}$ data: Based on the results $(\mathrm{M})$, large (L) and extra large (XL) (Table 3). Due to the possible contamination of the XS size class with detrital particles, we excluded this class from all further statistical analyses. We have, however, presented the vertical distribution of the XS group because this group contains small mesozooplankton. Common copepod species in the net samples were (1) the small omnivores Oithona spp. and Triconia spp., (2) the small- to medium-sized predominately herbivorous copepods of the genus Pseudocalanus, (3) the medium-sized omnivore Metridia sp. and (4) the larger, predominately herbivore Calanus finmarchicus. Based on OPC data we cannot discriminate between the small omnivores or between Pseudocalanus spp. and Metridia sp. (Herman \& Harvey 2006). Fortunately, the older development stages of $C$. finmarchicus occupy a distinct size range among the copepods (Herman 1992, Edvardsen 2001, Baumgartner 2003, Basedow et al. 2006); therefore their distribution can be analysed using the OPC. We chose the size class L for copepodite stage $\mathrm{V}(\mathrm{CV})$ and adult (CVI) C. finmarchicus to be especially narrow to minimise interference of other species into this size class. Noncopepod zooplankton that were common in the study area were small meroplanktic larvae $(<5 \%$ at the shelf during spring), hydrozoans ( $>20 \%$ in oceanic areas in summer), chaetognaths $(2.4 \%$ in oceanic areas in summer) and larvaceans (3.2 to $6.7 \%$ during all study periods). Hydrozoans had a diameter of $0.77 \pm 0.42 \mathrm{~mm}$ (mean \pm $\mathrm{SD}, \mathrm{n}=119$ ). Due to the transparency of hydrozoans, the OPC underestimates their diameter by 20 to $30 \%$ (Beaulieu et al. 1999, their Table IV). Thus, the hydrozoans in the present study were likely registered some- 
where between 0.25 and $0.95 \mathrm{~mm} \mathrm{ESD}$, i.e. in the XS and S size classes. Chaetognaths had a length of $6.89 \pm$ $1.32 \mathrm{~mm}$ (mean $\pm \mathrm{SD}, \mathrm{n}=53$ ), which corresponds to an ESD of $\sim 1.1$ to $1.5 \mathrm{~mm}$ when assuming that the ESD of chaetognaths equals ca. $20 \%$ its length (Beaulieu et al. 1999, their Table I); chaetognaths thus contributed to the $\mathrm{M}$ size class. The ESD of larvaceans is likely to vary substantially. Individuals with a new house will be relatively transparent and their ESD will be underestimated; individuals with an older housing that is clogged will be darker and hence will have a larger ESD. The houses of Oikopleura dioica are $\sim 4$ to $5 \mathrm{~mm}$ in diameter (Flood \& Deibel 1998), their ESD might thus vary between 3.2 and $5 \mathrm{~mm}$. Other Oikopleura species that are common in the Subarctic Atlantic have an even larger house (Flood \& Deibel 1998). Therefore, though we could not determine the species of Oikopleura, individuals probably had an ESD >3.2 mm. All Oikopleura spp. individuals fell thus into the XL size group. This group likely also contained larger invertebrates that were not captured by our sampling with the $180 \mu \mathrm{m}$ nets.

Preparation of data for statistical analyses. To condense the amount of data and to aid interpretation, we computed mean values of parameters for each survey of the water column: one value for each up-down coverage and one for each down-up coverage of the water column with the undulating instrument platform. The following parameters were computed for each profile: depth of the pycnocline, salinity/temperature/fluorescence above the pycnocline, salinity/temperature/fluorescence below the pycnocline, time of day, depth of the fluorescence maximum, abundance of XS/S/M/L/ $\mathrm{XL}$ zooplankton and, to be used as a response variable, the weighted mean depth (WMD) of L zooplankton. The water column of each profile was divided into depth layers $(\mathrm{d} z)$ of $1.5 \mathrm{~m}$ depth and WMD was computed as in Roe et al. (1984):

$$
\mathrm{WMD}=\sum_{i=1}^{z_{\max }} n_{i} z_{i} \mathrm{~d} z / \sum_{i=1}^{z_{\max }} n_{i} \mathrm{~d} z
$$

with $z_{i}$ being the mean depth of each $\mathrm{d} z, n_{i}$ the abundance of $\mathrm{L}$ zooplankton in that depth layer, and $z_{\max }$ the number of depth layers sampled during each profile. The pycnocline depth was defined as the depth where the maximum difference in potential density in the water column was observed.

Abundances were square root transformed to reduce skewness of the predictor variables. Salinity, temperature and depth of the pycnocline were strongly correlated to each other; to simplify the statistical analyses, we therefore used the depth of the pycnocline as an integrated measure of the physical conditions. Originally, we tried to fit one statistical model to the complete data set, and to model region and season depen- dence of parameters explicitly. This did not result in any stable statistical model; we therefore split the complete data set into two, an oceanic data set and a neritic data set, and successfully fitted a separate model to each area.

Selection of the statistical model. A variety of abiotic and biotic factors can potentially influence the vertical position of $\mathrm{CV}$ and adult Calanus finmarchicus, but the functional form of the response of the vertical position of copepods to many of these factors is not known. We therefore chose to fit a non-parametric model to the data, in which the exact functional form is not specified a priori but is instead determined from the data themselves. The data used in the present study were collected by an undulating instrument platform towed along transects; therefore autocorrelation has to be considered when fitting a statistical model to the data. Generalized additive mixed models (GAMMs) estimate additive non-parametric functions by smoothing splines to model covariate effects (Wood 2006). They also allow to model autocorrelation explicitly by adding random effects to the covariates (Lin \& Zhang 1999). For this reason, we analysed the data statistically by fitting alternative GAMMs, as implemented by the mgcv library (version 1.5-5; Wood 2004) in R (version 2.9.2; R Development Core Team 2009), to the data. The weighted mean depth (m) of the L zooplankton class ( $\mathrm{CV}$ and adult $C$. finmarchicus) as the response variable was modelled depending on physical and biological predictors. Predictor variables were added stepwise, i.e. step-by-step including (or removing) the variable that led to the largest reduction in Akaike's Information Criterion (AIC; Akaike 1974), but only retaining predictors that were statistically significant at the $5 \%$ level. Predictors considered were: season, depth of the pycnocline, fluorescence above and below the pycnocline, time of day, depth of the fluorescence maximum, and abundance of each zooplankton size class separately. Effects of continuous predictor variables were initially modelled as natural cubic spline functions with maximally 4 knots (i.e. 3 degrees of freedom). If a graphical inspection of the model showed a near linear relationship between response and predictor, a linear function was considered and selected if it resulted in a model with a lower AIC. After finding the best additive model, we considered models with interactions between the effects of season and other predictor variables. Interactions with smooth terms were modelled as season-specific splines; the statistical significance of these could then be assessed separately.

Both models (the neritic and the oceanic) included transect as a random effect and accounted for heteroscedasticity by modelling the error variance as exponential functions of the fitted values: estimated 
among-transect SD was 2.05 (95\% confidence interval CI: $1.40,2.99)$ for the oceanic model and 1.75 (CI: 0.29, 10.7) for the neritic model; estimated within-transect SD was 1.49 [CI: $1.33,1.67] \exp (0.039$ [CI: 0.035, 0.043] $x$ ) for the oceanic model and 2.64 [CI: 2.17, 3.22] $\exp (0.029$ [CI: $0.025,0.034] x)$ for the neritic model, with $x$ denoting the fitted values. Furthermore, we accounted for spatial autocorrelation within transects by modelling the error variance as autoregressive (AR) functions of observation number. For the oceanic model an order-1 AR-function was used (estimated AR-parameter: 0.61 [CI: 0.57, $0.64]$ ), and for the neritic model an order2 AR-function was selected (estimated AR-parameters: 0.628 [CI: 0.631, 0.613] and 0.19 [CI: 0.12, 0.25]). Alternative correlation structures (autoregressive-moving average, Gaussian, and exponential spatial functions) were considered, but these provided higher AIC values or did not converge.

Performance of the statistical model. The inspection of normalised residuals (standardised residuals pre-multiplied by the inverse square-root factor of the estimated error correlation matrix) of the final models did not reveal any obvious patterns or strong departures from normality. Some serial autocorrelation remained (llag 1-30 partial autocorrelations $\leq 0.14$ in the oceanic model, and $\leq 0.07$ in the neritic model), but this was judged to be too low to significantly influence statistical inferences in our study. Inspection of standardised residuals revealed 16 statistically significant outliers (Grubbs 1969, Stefansky 1972) in the oceanic data set $(n=2848)$ and 9 in the neritic data set $(n=1226)$, and we confirmed that results did not depend qualitatively on these observations by refitting the final models with the outliers removed.

Fig. 2. Spring. Distribution of hydrography (top 3 panels), fluorescence and different zooplankton size groups (lower 5 panels) along 2 typical transects from a neritic (left) and an oceanic (right) area. Data were sampled by a towed instrument platform equipped with CTD-FLOPC in 2002-2003. See Table 3 for details on size classes
Neritic

Longitude $\left({ }^{\circ} \mathrm{E}\right)$
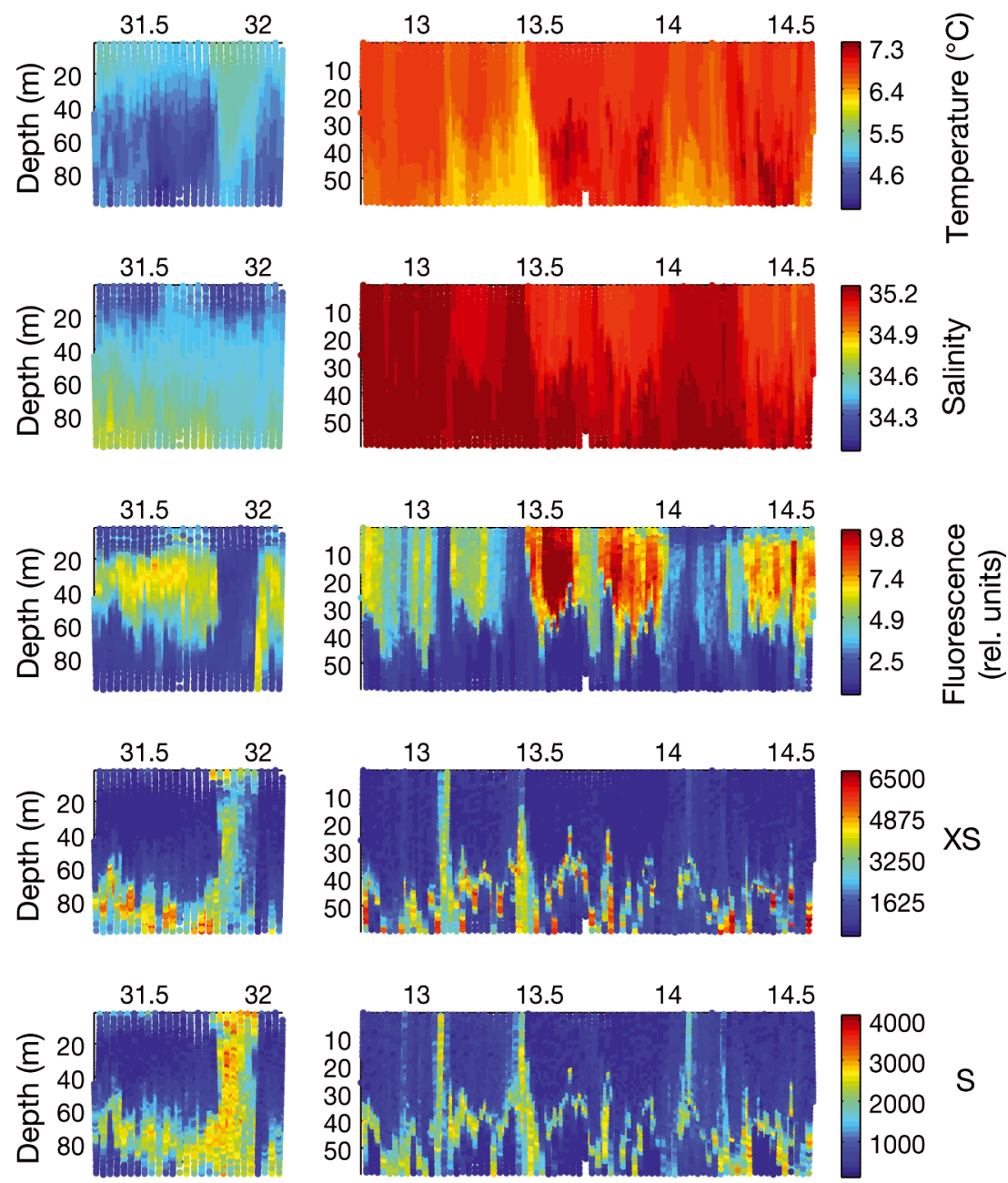

$S$
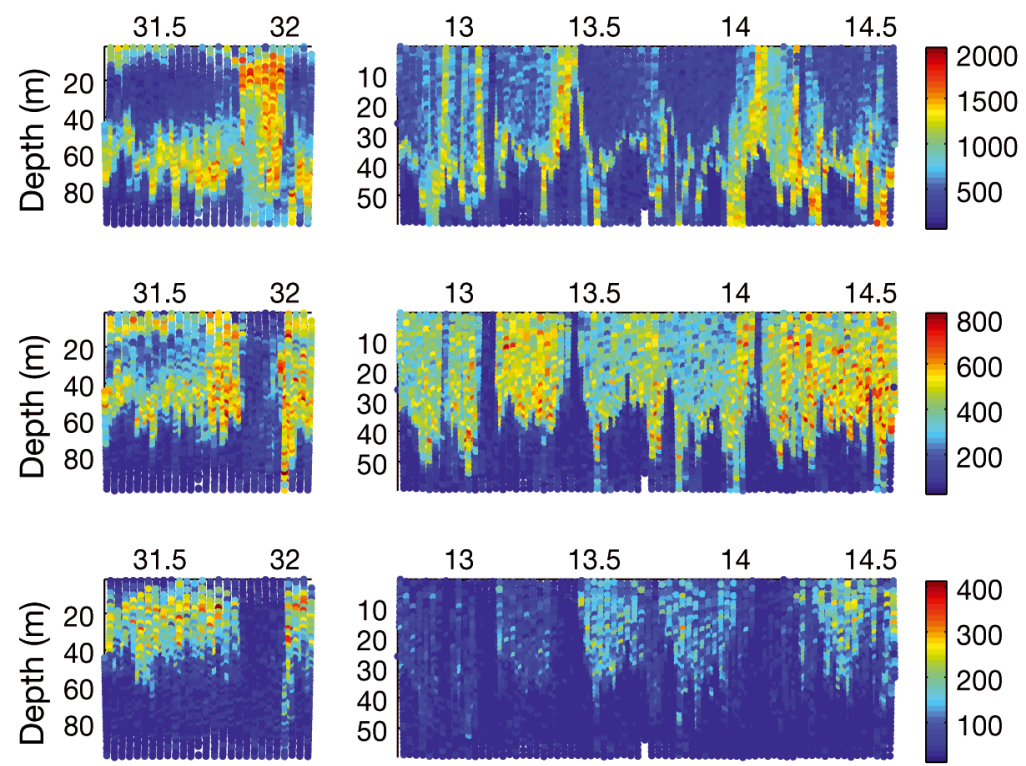

$\mathrm{XL}$ 


\section{RESULTS}

\section{Hydrography}

During spring, the neritic area in the southern Barents Sea was dominated by water of coastal origin (salinity <34.7; Sakshaug et al. 1994), but in the deeper layers $>70 \mathrm{~m}$ in the west intrusions of denser, more saline water (>34.7) were observed (Fig. 2). The pycnocline lay at $60 \mathrm{~m}$ in the west and slightly deeper in the east, and the upper layer appeared to be wellmixed with temperatures ranging from 3.7 to $5.4{ }^{\circ} \mathrm{C}$. The oceanic habitat in the Norwegian Sea was dominated by Atlantic water (AW; Fig. 2), which is defined by a salinity $>35.0$ and temperatures $>0{ }^{\circ} \mathrm{C}$ (Swift 1986). But also lenses of mixed Atlantic and coastal water, defined by a salinity between 34.8 and 35.0 (Swift 1986), occurred in the oceanic area, mostly close to the shelf in the east. Stratification in the oceanic area during spring was only weakly developed and temperatures were relatively constant throughout the area, ranging between 6 and $7.3^{\circ} \mathrm{C}$.

During early summer, the neritic area in the northern Norwegian Sea was dominated by coastal water with a salinity <34.8 (Johannessen 1986) (Fig. 3). Stratification during this time of the year was well developed with a shallow pycnocline around $30 \mathrm{~m}$ in the northern and $20 \mathrm{~m}$ in the southern part of the neritic area. Temperatures were warmer than in the neritic area visited during spring and ranged from 5.5 to $8.4^{\circ} \mathrm{C}$. In the oceanic area, AW dominated also during summer (Fig. 3). As in the neritic area, also here a shallow pycnocline around $30 \mathrm{~m}$ had developed. Temperatures in the upper layer were slightly warmer compared to the cruise in spring.

\section{Vertical distribution of fluorescence and zooplankton size classes}

During spring on the shelf, sub-surface maxima of fluorescence at around $30 \mathrm{~m}$ were observed (Fig. 2). Along the longitudinal transects, these areas with subsurface maxima were separated by areas where fluorescence was homogeneously low in the water column. Zooplankton size classes were distributed according to a clear and consistent pattern throughout the investigated shelf area: where sub-surface maxima were

Fig. 3. Summer. Distribution of hydrography (top 3 panels), fluorescence and different zooplankton size groups (lower 5 panels) along 2 typical transects from a neritic (left) and an oceanic (right) area. Data were sampled by a towed instrument platform equipped with CTD-F-LOPC in 2001 and 2003. See Table 3 for details on size groups
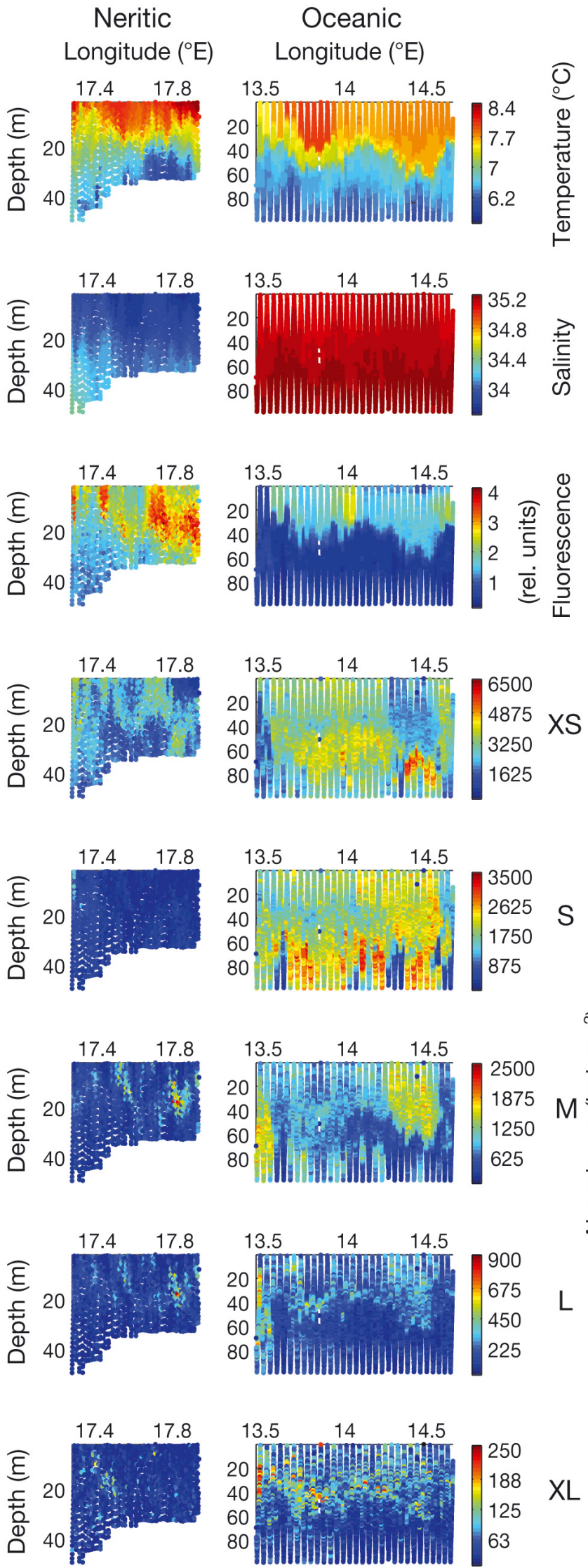

$\mathrm{XL}$ 
found, XL zooplankton was observed at the fluorescence maximum; L zooplankton was also observed at the fluorescence maximum or, when fluorescence was very high, slightly above and below the maximum; $M$ zooplankton occurred right below the fluorescence maximum; S zooplankton resided below $\mathrm{M}$ zooplankton; and farthest down in the water column the smallest zooplankton organisms (XS) were observed. Where fluorescence was homogeneously low, XL and L were virtually absent while $\mathrm{M}, \mathrm{S}$ and XS were distributed relatively homogeneously along the depth axis.

During spring in the oceanic area, both surface and sub-surface maxima of fluorescence were observed (Fig. 2); surface maxima were more common during the beginning of the cruise. Patches of high fluorescence alternated with areas where fluorescence was homogeneously low. The pattern of zooplankton distribution resembled very closely the distribution pattern observed at the shelf; with XS zooplankton residing farthest down in the water column, S slightly higher, M below areas of maximum fluorescence and $\mathrm{L}$ and XL at the fluorescence maximum. As in the neritic area, L zooplankton occurred also above and below fluorescence maxima if these were very high. Also where fluorescence was homogeneously low, the distribution

Table 4. Results of the generalized additive mixed models (GAMMs), which modelled the vertical position of large zooplankton (older stages of Calanus finmarchicus) depending on abiotic and biotic predictors. GAMMs were fitted separately to data from oceanic $\left(\mathrm{r}^{2}{ }_{\text {adj }}=0.56, \mathrm{n}=2848\right)$ and neritic $\left(\mathrm{r}^{2}{ }_{\text {adj }}=0.52\right.$, $\mathrm{n}=1226$ ) habitats of the Barents and Norwegian Seas in spring and summer 2001-2003. Parameter estimates with SE and $t$-values for linear covariates, and estimated degrees of freedom (edf) and $F$-values for smooth-term covariates are given. All predictors selected were highly significant in the models $(p<0.001)$. Flu $=$ fluorescence below the pycnocline; S, M, L, XL = abundance of small, medium, large and extra large zooplankton, respectively (see Table 3 for details). Season: summer $=1$, spring $=0$; PycDep = depth of the pycnocline $(\mathrm{m})$; FluMaxDep = depth of fluorescence maximum. For the neritic model, Flu, M and XL were not selected among the predictor variables and $\mathrm{S}$ is the abundance of small zooplankton during spring only because it was not significant during summer. na = not applicable

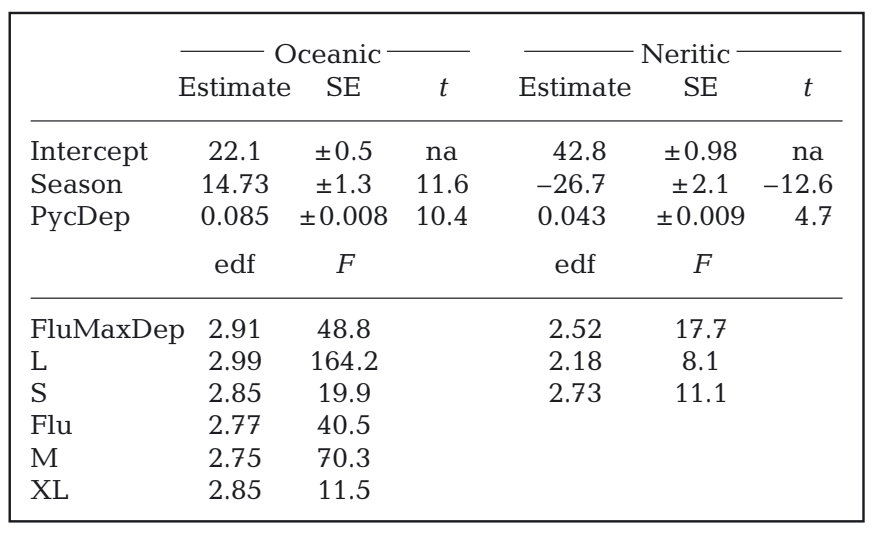

pattern of zooplankton was practically identical to the one observed in the neritic area: with the virtual absence of XL and L zooplankton and homogeneous distribution of $\mathrm{M}, \mathrm{S}$ and XS.

Later in the season during early summer, fluorescence in the neritic areas in the Norwegian Sea was generally lower than observed on the shelf during spring. Both surface and sub-surface maxima of fluorescence were observed, with sub-surface maxima occurring more frequently close to the shore and surface maxima more frequently farther offshore (Fig. 3). Zooplankton was less abundant compared to the Barents Sea shelf in spring, making it difficult to distinguish distribution patterns visually. However, the relationship between fluorescence and zooplankton distribution appeared to be less consistent during summer than during spring in neritic areas.

In the oceanic area, surface and sub-surface maxima of fluorescence were observed during early summer (Fig. 3). XL zooplankton occurred mostly below fluorescence maxima, whereas a visual inspection of the distribution of L, M, S and XS zooplankton did not reveal any clear pattern in relation to fluorescence or to each other.

\section{Effect of different parameters on the vertical distribution of $\mathrm{CV}$ and adult female Calanus finmarchicus}

The L zooplankton size class consisted of CV and adult female Calanus finmarchicus (Table 3); we therefore talk about the older development stages (CV and adults) as a synonym for L zooplankton. We found strong effects of season on the weighted mean depth of older development stages of $C$. finmarchicus (Table 4). The effect of season seems largely to reflect differences in sampling depths among cruises; these increased from spring to summer in oceanic areas, and decreased in neritic habitat (Table 1). Data were collected continuously during night and day, but no effect of the time of the day on the weighted mean depth of older $C$. finmarchicus was detected in the statistical analysis, demonstrating a lack of synchronous diel vertical migration in spring and early summer, both in neritic and oceanic areas.

Hydrography was represented by the depth of the pycnocline in our statistical analyses and was significant for both neritic and oceanic areas (Tables 5 \& 6). If the mixed layer extended farther down, CV and adult female $C$. finmarchicus were found deeper in the water column (Figs. $4 \& 5$ ). The depth of the pycnocline was selected among the last parameters during model selection (Tables $5 \& 6$ ), i.e. the effect of hydrography was secondary to the effect of e.g. the depth of the fluorescence maximum. 
Table 5. Contribution of covariates to the generalized additive mixed model fitted to data from neritic areas $\left(\mathrm{r}^{2}{ }_{\text {adj }}=0.52\right.$, $\mathrm{n}=1226)$. The vertical position of large zooplankton (CV and adult Calanus finmarchicus) was modelled depending on physical and biological factors, based on data collected in the Norwegian and Barents Seas in spring and summer 2001-2002. Left columns show the adjusted coefficient of determination $\left(\mathrm{r}^{2}\right.$ adj $)$ and the value of Akaike's Information Criterion (AIC) after stepwise addition of one covariate to the model (first depth of fluorescence maximum, FluMaxDep; then Season etc.). Right columns show $\mathrm{r}^{2}$ adj and AIC for the models from which one covariate (listed to the left) was removed while keeping the others. Season: summer $=1$, spring $=0 ;$ PycDep = depth of the pycnocline; $\mathrm{L}=$ abundance of large zooplankton; S spring = abundance of small zooplankton during spring; during summer small zooplankton was not among the selected predictors of the model. Note that $\mathrm{r}^{2}$ adj can become negative if the adjustment for the degrees of freedom is large

\begin{tabular}{|lcccc|}
\hline & \multicolumn{2}{c}{$\begin{array}{c}\text { Stepwise addition } \\
\mathrm{r}^{2}{ }_{\text {adj }}\end{array}$} & AIC & \multicolumn{2}{c|}{$\begin{array}{c}\text { Delete-one-covariate } \\
\mathrm{r}^{2}{ }_{\text {adj }}\end{array}$} & AIC \\
\hline FluMaxDep & $<0$ & 7864 & 0.58 & 7806 \\
Season & 0.39 & 7794 & $<0$ & 7787 \\
L & 0.52 & 7745 & 0.39 & 7736 \\
S spring & 0.54 & 7716 & 0.49 & 7722 \\
PycDep & 0.52 & 7696 & 0.54 & 7716 \\
& & & & \\
\hline
\end{tabular}
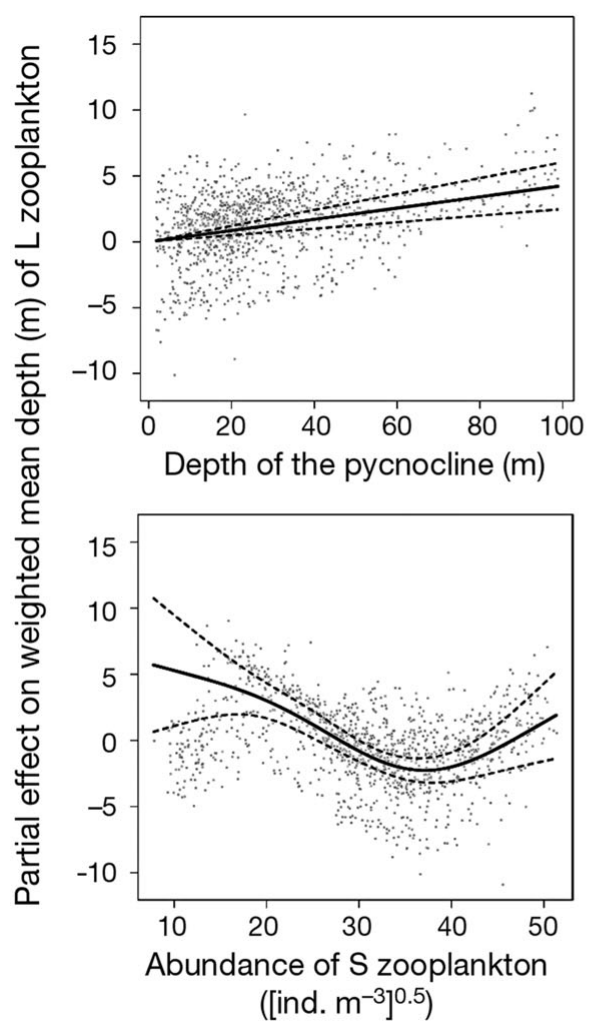

Table 6. Contribution of physical and biological covariates to the generalized additive mixed model (GAMM) that modelled the vertical position of large zooplankton residing in oceanic areas $\left(r^{2}\right.$ adj $\left.=0.56, n=2848\right)$. The GAMM was fitted to data collected in the Norwegian Sea in spring and summer 2003. Left columns show the adjusted coefficient of determination $\left(\mathrm{r}_{\text {adj }}^{2}\right)$ and the value of Akaike's Information Criterion (AIC) after stepwise addition of one covariate to the model. Right columns show $\mathrm{r}^{2}$ adj and AIC for the models from which one covariate (listed to the left) was removed while keeping the others. When fluorescence below the pycnocline (Flu) was deleted, the model did not converge. Season: summer $=1$, spring $=0$; PycDep $=$ depth of the pycnocline; FluMaxDep = depth of fluorescence maximum; $\mathrm{S}, \mathrm{M}, \mathrm{L}, \mathrm{XL}=$ abundance of small, medium, large and extra large zooplankton, respectively. Note that $\mathrm{r}^{2}$ adj can become negative if the adjustment for the degrees of freedom is large

\begin{tabular}{|lcccc|}
\hline & \multicolumn{2}{c|}{$\begin{array}{c}\text { Stepwise } \\
\text { r }{ }^{2} \text { adj }\end{array}$} & AIC & \multicolumn{2}{c|}{$\begin{array}{c}\text { Delete-one-covariate } \\
\mathrm{r}^{2}{ }_{\text {adj }}\end{array}$} & AIC \\
\hline L & $<0$ & 16030 & 0.13 & 15553 \\
FluMaxDep & $<0$ & 15571 & 0.65 & 15293 \\
M & 0.29 & 15271 & 0.39 & 15158 \\
S & 0.27 & 15214 & 0.59 & 15004 \\
Flu & 0.27 & 15119 & \multicolumn{2}{c}{ no convergence } \\
PycDep & 0.27 & 15035 & 0.60 & 15048 \\
Season & 0.55 & 14989 & 0.29 & 15019 \\
XL & 0.56 & 14974 & 0.55 & 14989 \\
\hline
\end{tabular}
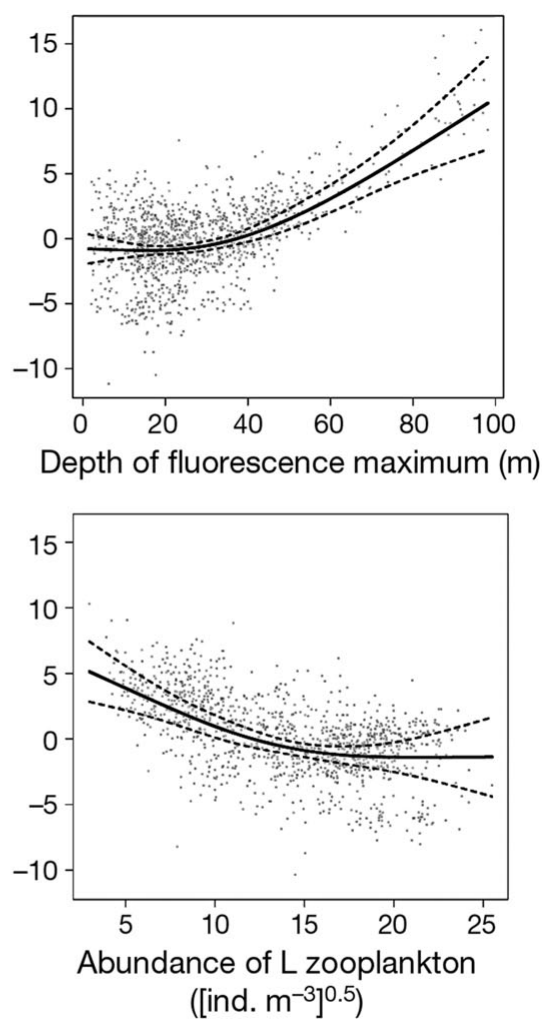

Fig. 4. Neritic areas. Effect of abiotic and biotic factors on the vertical distribution (weighted mean depth) of large (L) zooplankton. Shown is the partial effect (solid line), i.e. the effect of that factor only, of each significant factor according to a generalized additive mixed model. $95 \%$ confidence intervals (dashed lines) and residuals (grey dots) are depicted as well. The effect of small (S) zooplankton is only for spring (see Table 5). Based on data sampled by a semi-automatic sampling platform during spring and early summer 2001-2002 in the Norwegian and Barents Seas 


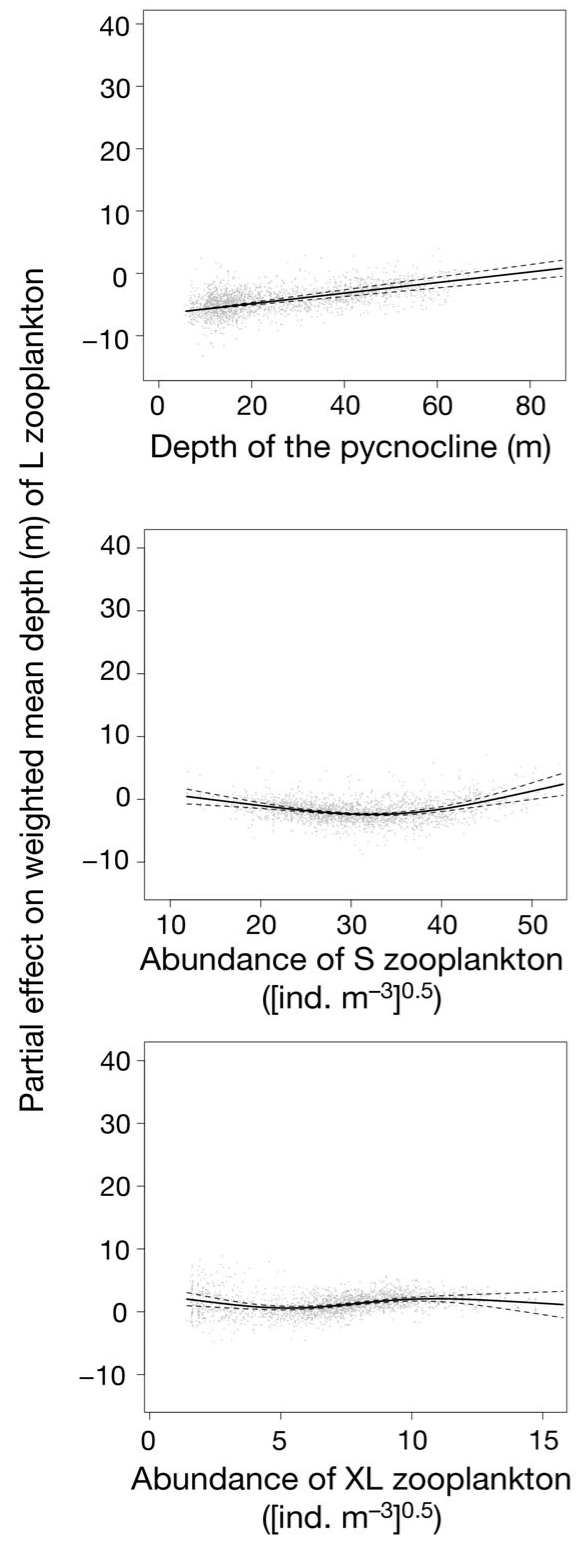

The depth of the fluorescence maximum was among the first predictors selected in the GAMM. The effect was significant for both neritic and oceanic areas (Tables 5 \& 6). When the fluorescence maximum was at $30 \mathrm{~m}$ or less, no effect on the depth distribution of Calanus finmarchicus was observed. If the depth of the fluorescence maximum was $>30 \mathrm{~m}$, however, CV and adult females were found progressively deeper in the water column, both on the shelf and in the open ocean (Figs. 4 \& 5). In addition to the depth of the fluorescence maximum, in oceanic areas the depth of older stages of $C$. finmarchicus was also correlated to the amount of fluorescence below the pycnocline. Older stages were found deeper in the water column when fluorescence below the pycnocline increased above a critical value of about 3 (Table 6, Fig. 5).
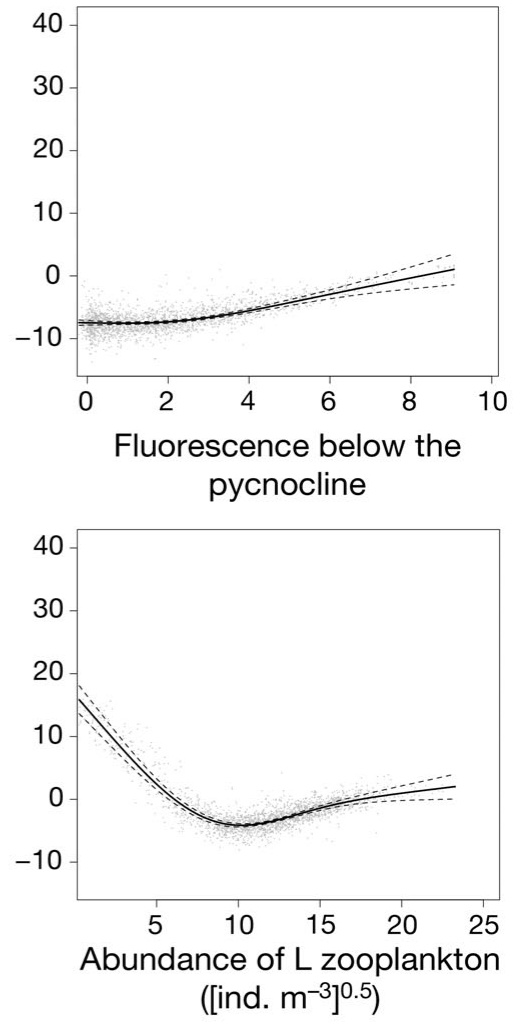

([ind. $\left.\mathrm{m}^{-3}\right]^{0.5}$ )
Fig. 5. Oceanic areas. Effect of abiotic and biotic factors on the vertical distribution (weighted mean depth) of large (L) zooplankton. Shown is the partial according to a generalized additive mixed model. 95\% confidence intervals (dashed lines) and residuals (grey dots) are depicted as well. Based on data sampled by a semi-automatic instrument platform in spring and early summer 2003 in the Norwegian Sea. S, M, XL: small, medium and extra large zooplankton

We found nonlinear effects of $\mathrm{S}$ zooplankton on the depth of larger Calanus finmarchicus for both neritic and oceanic areas. The weighted mean depth of CV and adult Calanus sp. decreased significantly when abundance of $\mathrm{S}$ zooplankton increased up to $\sim 1500$ ind. $\mathrm{m}^{-3}$ (Figs. 4 \& 5). When abundance of $\mathrm{S}$ zooplankton became higher than 1500 ind. $\mathrm{m}^{-3}$, however, older $C$. finmarchicus were located deeper in the water column again (Figs. 4 \& 5). For neritic areas, this effect of $\mathrm{S}$ zooplankton did not depend on season, whereas for oceanic areas the effect was observed in spring only (Tables 5 \& 6).

M zooplankton was selected among the predictor variables only in the oceanic model (Table 6). In oceanic areas, in addition to CIV copepodites of Calanus finmarchicus, chaetognaths contributed to the $\mathrm{M}$ 
zooplankton size class (Table 3). They were, however, 10 times less abundant than CIV copepodites (Table 2). Weighted mean depth of older C. finmarchicus increased with increasing abundance of $\mathrm{M}$ zooplankton (Fig. 5).

A strong density-dependence of the weighted mean depth of CV and adult female Calanus finmarchicus was detected, both in neritic (Fig. 4) and oceanic areas (Fig. 5). L zooplankton were found deep in the water column when their abundance was low, but were observed gradually closer to surface until abundances were around 100 to 200 ind. $\mathrm{m}^{-3}$. In oceanic areas, older $C$. finmarchicus were found deeper in the water column, again if abundances reached values higher than 200 ind. $\mathrm{m}^{-3}$.

The XL size class, which included Appendicularia and likely also invertebrate predators not caught by the nets, were significant as predictor variable for oceanic areas only (Table 6). The effect was not very strong, but indicated shallower distribution of Calanus finmarchicus at intermediate, compared to both low and high abundances of XL zooplankton (Fig. 5).

\section{DISCUSSION}

Older developmental stages of the marine copepod Calanus finmarchicus seemed to select their vertical position in the upper water column primarily in response to biotic factors. The vertical position of CV and adults was strongly correlated to the depth of the fluorescence maximum and to the abundance of different zooplankton size classes. This was revealed by the thorough analyses of 4 extensive physical and biological high-resolution data sets. As expected, hydrography also influenced the vertical position of $\mathrm{CV}$ and adult $C$. finmarchicus. Copepods were observed deeper in the water column when the depth of the pycnocline increased. Pycnocline depth, however, was selected as explanatory variable only after biotic factors in the statistical analyses.

There were about $4 \mathrm{wk}$ between the 'spring' and the 'summer' sampling, both in the neritic and in the oceanic habitats. The samplings do not represent an early spring situation vs. a late summer situation, but rather represent a continuous development from the spring situation, when females of the $\mathrm{G}_{0}$ generation dominate among the older development stages, to the summer situation, when CV copepodites of the $\mathrm{G}_{1}$ generation dominate among the older stages. The neritic area was visited relatively late in spring. Sub-surface fluorescence maxima had developed, and the Calanus sp. population was already centred around CI-CIII copepodites. Few males were present, suggesting continued spawning activity of females. The ratio between females and CV was low (0.15), clearly indicating that the $G_{1}$ generation dominated in the neritic area in spring. The oceanic area was visited earlier in spring. Here, the Calanus sp. population was centred around nauplii in spring. The ratio between females and $\mathrm{CV}$ copepodites decreased from 1.44 in spring to 0.19 in summer. A clear shift from $\mathrm{G}_{0}$ to $\mathrm{G}_{1}$ generation is therefore likely to have happened among $\mathrm{CV}$ and adult female Calanus finmarchicus in the oceanic area during our study period (see also Basedow et al. 2006).

The weighted mean depth of older copepods (CV and adult females) was significantly correlated to 'season' in the statistical model. However, this correlation was most likely not due to an effect of season per se, but can be explained by the different sampling depths during each season (Table 1). By taking account of the effect of sampling depth on the weighted mean depth of copepods in this way, we obtained correlations for the other parameters that are not affected by sampling depth.

The strong correlation of the depth of CV and adult Calanus finmarchicus to the depth of the fluorescence maximum was one of the most important results obtained, and suggests that the copepods selected their vertical position primarily in response to the availability of phytoplankton food during the productive season in the Subarctic. C. finmarchicus is a predominately herbivorous feeder, but grazes also on microzooplankton, especially outside phytoplankton bloom situations (Nielsen \& Kiørboe 1994, Ohman \& Runge 1994, Calbet \& Saiz 2005). Throughout most of the field surveys presented in the present study, high fluorescence values were observed either at the surface or in deeper layers. High-quality phytoplankton food therefore might have been available to the copepods at most locations investigated during both seasons. Food availability and quality likely were homogeneously distributed in the well-mixed upper metres, which can explain the observed nonlinear response curve in relation to the depth of the fluorescence maximum: older stages of $C$. finmarchicus were observed deeper in the water column only when fluorescence maxima had developed in deeper waters (>30 m).

The other major parameter that was correlated to the vertical distribution of older copepodite stages of Calanus sp. was copepod density. Vertical position of $\mathrm{CV}$ and adult female Calanus sp. was correlated both to the abundance of S zooplankton (mostly CII and CIII copepodites) and to the abundance of L zooplankton (CV and adult females). Swarming behaviour by copepods is one mechanism that might have caused the observed relationship between copepod density and vertical position of CV and adult Calanus finmarchicus (Ambler 2002). Per capita predation risk is reduced at high abundances, and the layer close to the surface is 
usually the layer where predation risk is highest. Copepods could therefore risk staying closer to the surface with increasing abundance, and this might explain why $\mathrm{CV}$ and adults were observed closer to surface when abundance of CII-CIII copepodites (S zooplankton), and of $\mathrm{CV}$ and adults, increased. At very high abundances, weighted mean depth of $\mathrm{CV}$ and adult females appeared to increase again. One possible reason for such an increase in mean depth could be the expansion of the depth range occupied by copepods. That is, a larger fraction of the population might have been 'forced' to deeper depths at very high densities, because of competition between copepods (Fretwell \& Lucas 1969). An alternative explanation for the found effect of population density on vertical distribution could be small-scale spatiotemporal variability in the seasonal development within each observation period (spring and summer). Mesoscale oceanographic features can lead to a heterogeneous development in zooplankton populations over small spatial scales (Huntley et al. 2000, Basedow et al. 2006). Variability in abundance of $\mathrm{CV}$ and adult female Calanus sp. might then reflect a variability in population development and ontogenetic changes in depth distribution, with females ascending in spring and CV copepodites descending in summer. However, CV copepodites generally dominated over females in the L zooplankton group, except during spring in the oceanic area. Therefore, one would expect that high abundance of $\mathrm{L}$ zooplankton in this study reflects advanced population development, and would thus expect to find a deeper distribution of copepods at higher abundance. This is the opposite of the most prominent pattern observed in the data, especially in neritic areas. We therefore do not think spatiotemporal variability in population development is a main factor explaining the effect of population density on depth distribution. We rather believe the found effects of copepod density on their vertical position are effects of population density per se.

No biologically significant differences between neritic and oceanic areas were observed in the response of CV and adult Calanus sp. to the depth of the pycnocline, the depth of the fluorescence maximum, the abundance of $\mathrm{S}$ zooplankton or to the abundance of $\mathrm{L}$ zooplankton. That is, the form of the response curves of weighted mean depth of CV and adults to the mentioned parameters strongly resembled each other in the analyses of the neritic and the oceanic data sets. This might be explained by the similarity between the analysed habitats, but shows also that the correlations hold when tested in different areas. The Subarctic habitats that were analysed in this study were similar with respect to hydrography. Both neritic habitats, one in the Norwegian Sea and one in the Barents Sea, were dominated by coastal water, while both oceanic habitats were dominated by Atlantic water. Weak stratification was observed both in the neritic and in the oceanic habitat during spring; later in the season a shallow pycnocline had developed in both habitats. In the oceanic environment $\mathrm{M}$ and XL zooplankton were also correlated to the depth of older Calanus finmarchicus. These groups contained more potential predators of $C$. finmarchicus in the oceanic areas compared to the neritic areas (Table 3). Therefore, the cause for an observed correlation between $\mathrm{M}$ and XL zooplankton to the vertical position of older Calanus $\mathrm{sp}$. in the oceanic areas was probably related to a different composition of zooplankton size classes in the oceanic areas compared to the neritic areas.

No synchronous diel vertical migrations (DVM) of older stages of Calanus sp. were observed, either in spring or in summer. Copepods adjusted their position in the water column in relation to other factors than light instead. In an earlier analysis of the oceanic data set from spring, Basedow et al. (2008) found a weak effect of DVM. They analysed the data by constrained correspondence analysis, which, in contrast to the GAMM that was used in the present study, does not account for autocorrelation. The selection of explanatory variables in the GAMM is therefore more conservative, which could explain the differences between the 2 analyses. Our samplings were all carried out close to or during the period of midnight sun, but even small changes in light level can induce DVM (Ringelberg 1995). The ultimate factor for DVM in all likelihood is predator evasion, and often DVM is stronger when predators are abundant (reviewed by Hays 2003). In the neritic area that was visited in late spring, juvenile cod did prey on older stages of Calanus sp. during summer and might have done so in late spring as well (Hallfredsson \& Pedersen 2007). In the oceanic area too, predation by gelatinous zooplankton and by fish is generally likely during summer (Kaartvedt 2000, Dale et al. 2001). On the other hand, synchronous DVM of Calanus finmarchicus is not very pronounced in the temperate NE Atlantic and seems to be absent in the Arctic (Hays 1996, Blachowiak-Samolyk et al. 2006). Our results suggest that synchronous DVM of Calanus sp. is also absent during the productive period in the Subarctic.

A detailed analysis of a considerable amount of field data with high spatial resolution was presented here. To our knowledge, the present study is the first field study where both physical and biological data were collected with sufficiently high resolution to allow analysing differences in habitat choice by a marine copepod throughout the productive season in the Subarctic. The results from 4 time snap shots during the productive season suggest that older stages of Calanus 
finmarchicus dynamically and consistently select their habitat based on food conditions and predators in a density-dependent manner. Although our study is confined to copepods and environmental interactions, the findings might encourage broader future studies covering several trophic levels in the marine habitat. We conclude that ecological interactions may drive habitat choice of planktonic organisms even in highly fluctuating oceanic environments.

Acknowledgements. We thank the helpful crews aboard RV 'Johan Ruud' and RV 'Jan Mayen'. Further, we thank R. Buvang and J.-T. Eilertsen for technical assistance. We also thank 4 anonymous reviewers for comments on an earlier version of the manuscript that helped significantly improve the article. This study was funded by the Norwegian Research Council through the projects 'Plankton Climatology in the Barents Sea' (project no. 133904/120) and 'Capelin and herring in the Barents Sea - coexistence or exclusion' (project no. 140290/140). S.B. was financed through the IPY project 'Norwegian Component of the Ecosystem Studies of Subarctic and Arctic Regions (NESSAR)' (project no. 76057/S30). L.C.S. thanks the Norwegian Research Council (project no. 178434/ S40) for support.

\section{LITERATURE CITED}

Akaike H (1974) A new look at statistical model identification. IEEE Trans Automat Contr 19:716-722

> Ambler JW (2002) Zooplankton swarms: characteristics, proximal cues and proposed advantages. Hydrobiologia 480:155-164

Basedow SL, Edvardsen A, Tande KS (2006) Spatial patterns of surface blooms and recruitment dynamics of Calanus finmarchicus in the NE Norwegian Sea. J Plankton Res 28:1181-1190

Basedow SL, Edvardsen A, Tande KS (2008) Vertical segregation of Calanus finmarchicus copepodites during the spring bloom. J Mar Syst 70:21-32

Baumgartner MF (2003) Comparisons of Calanus finmarchicus fifth copepodite abundance estimates from nets and an optical plankton counter. J Plankton Res 25:855-868

Beaulieu SE, Mullin MM, Tang VT, Pyne SM, King AL, Twinning BS (1999) Using an optical plankton counter to determine the size distributions of preserved zooplankton samples. J Plankton Res 21:1939-1956

Begon M, Townsend CR, Harper JL (eds) (2006) Ecology, 4th edn. Blackwell Publishing, Oxford

Blachowiak-Samolyk K, Kwasniewski S, Richardson K, Dmoch K and others (2006) Arctic zooplankton do not perform diel vertical migration (DVM) during periods of midnight sun. Mar Ecol Prog Ser 308:101-116

Calbet A, Saiz E (2005) The ciliate-copepod link in marine ecosystems. Aquat Microb Ecol 38:157-167

> Conover RJ (1988) Comparative life histories in the genera Calanus and Neocalanus in high latitudes of the northern hemisphere. Hydrobiologia 167/168:127-142

Cottier FR, Tarling GA, Wold A, Falk-Petersen S (2006) Unsynchronized and synchronized vertical migration of zooplankton in a high arctic fjord. Limnol Oceanogr 51: 2586-2599

> Dale T, Kaartvedt S, Ellertsen B, Amundsen R (2001) Largescale oceanic distribution and population structure of Calanus finmarchicus in relation to physical food and predators. Mar Biol 139:561-574
Dalpadado P, Ellertsen B, Melle W, Dommasnes A (2000) Food and feeding conditions of Norwegian spring spawning herring (Clupea harengus) through its feeding migrations. ICES J Mar Sci 57:843-857

> Durbin EG, Campbell RC, Gilman SL, Durbin AG (1995) Diel feeding behavior and ingestion rate in the copepod Calanus finmarchicus in the southern Gulf of Maine during late spring. Cont Shelf Res 15:539-570

Edvardsen A (2001) Biophysical rates of zooplankton: a study of methods for measurement of zooplankton dynamics. PhD thesis, University of Tromsø

Edvardsen A, Zhou M, Tande KS, Zhu YW (2002) Zooplankton population dynamics: measuring in situ growth and mortality rates using an Optical Plankton Counter. Mar Ecol Prog Ser 227:205-219

> Edvardsen A, Pedersen J, Slagstad D, Semenova T, Timonin A (2006) Distribution of overwintering Calanus in the North Norwegian Sea. Ocean Science 2:87-96

Eiane K, Aksnes DL, Ohman MD, Wood S, Martinussen MB (2002) Stage-specific mortality of Calanus spp. under different predation regimes. Limnol Oceanogr 47:636-645

- Fiksen O (2000) The adaptive timing of diapause - a search for evolutionary stable strategies in Calanus finmarchicus. ICES J Mar Sci 57:1825-1833

Fiksen O, Carlotti F (1998) A model of optimal life history and diel vertical migration in Calanus finmarchicus. Sarsia 83:129-147

Flood PR, Deibel D 1998. The appendicularia house. In: Bone Q (ed) The biology of pelagic tunicates. Oxford University Press, New York, NY, p 105-124

> Fossheim M, Primicerio R (2008) Habitat choice by marine zooplankton in a high-latitude ecosystem. Mar Ecol Prog Ser 364:47-56

Fretwell SD, Lucas HLJ (1969) On territorial behavior and other factors influencing habitat distribution in birds. I. Theoretical development. Acta Biotheor 19:16-36

- Fromentin JM, Planque B (1996) Calanus and environment in the eastern North Atlantic. 2. Influence of the North Atlantic Oscillation on C. finmarchicus and C. helgolandicus. Mar Ecol Prog Ser 134:111-118

Gislason A, Astthorsson OS, Petursdottir H, Gudfinnsson H, Bodvarsdottir AR (2000) Life cycle of Calanus finmarchicus south of Iceland in relation to hydrography and chlorophyll a. ICES J Mar Sci 57:1619-1627

- Grubbs F (1969) Procedures for detecting outlying observation in samples. Technometrics 11:1-21

Hallfredsson EH, Pedersen T (2007) Effects of predation from pelagic 0-group cod (Gadus morhua) on mortality rates of capelin (Mallotus villosus) larvae in the Barents Sea. Can J Fish Aquat Sci 64:1710-1722

Halvorsen E, Tande K (1994) Physical and biological factors influencing the seasonal variation in distribution of zooplankton across the shelf at Nordvestbanken, northern Norway, 1994. Sarsia 84:280-292

Hays GC (1996) Large-scale patterns of diel vertical migration in the North Atlantic. Deep-Sea Res I 43:1601-1615

Hays GC (2003) A review of the adaptive significance and ecosystem consequences of zooplankton diel vertical migrations. Hydrobiologia 503:163-170

Hays GC, Warner AJ, Lefevre D (1996) Long-term changes in the diel vertical migration behaviour of zooplankton. Mar Ecol Prog Ser 141:149-159

> Heath MR, Boyle PR, Gislason A, Gurney WSC and others (2004) Comparative ecology of over-wintering Calanus finmarchicus in the northern North Atlantic, and implications for life-cycle patterns. ICES J Mar Sci 61:698-708

Herman AW (1992) Design and calibration of a new optical 
plankton counter capable of sizing small zooplankton. Deep-Sea Res I 39:395-415

Herman AW, Harvey M (2006) Application of normalized biomass size spectra to laser optical plankton counter net intercomparisons of zooplankton distributions. J Geophys Res 111:C05S05 doi:10.1029/2005JC002948

Hirst AG, Bunker AJ (2003) Growth of marine planktonic copepds: global rates and patterns in relation to chlorophyll $a$, temperature, and body weight. Limnol Oceanogr 48:1988-2010

Hugie DM, Dill LM (1994) Fish and game: a game theoretic approach to habitat selection by predators and prey. J Fish Biol 45:151-169

> Huntley M, Gonzalez A, Zhu Y, Zhou M, Irigoien X (2000) Zooplankton dynamics in a mesoscale eddy-jet system off California. Mar Ecol Prog Ser 201:165-178

Johannessen OM (1986) Brief overview of the physical oceanography. In: Hurdle G (ed) The Nordic Seas. Springer Verlag, Berlin, p 103-126

Kaartvedt S (2000) Life history of Calanus finmarchicus in the Norwegian Sea in relation to planktivorous fish. ICES J Mar Sci 57:1819-1824

Kattner G, Krause M (1987) Changes in lipids during the development of Calanus finmarchicus s. l. from Copepodid I to adult. Mar Biol 96:511-518

Lampert W, McCauley E, Manly BFJ (2003) Trade-offs in the vertical distribution of zooplankton: ideal free distribution with costs? Proc Biol Sci 270:765-773

Lin X, Zhang D (1999) Inference in generalized additive mixed models by using smoothing splines. J R Stat Soc, B 61:381-400

Longhurst AR, Harrison WG (1989) The biological pump: profiles of plankton production and consumption in the upper ocean. Prog Oceanogr 22:47-123

Neill WE (1990) Induced vertical migration in copepods as a defense against invertebrate predation. Nature 345: 524-526

- Niehoff B, Klenke U, Hirche HJ, Irigoien X, Head R, Harris R (1999) A high frequency time series at Weathership $M$, Norwegian Sea, during the 1997 spring bloom: the reproductive biology of Calanus finmarchicus. Mar Ecol Prog Ser 176:81-92

Nielsen TG, Kiørboe T (1994) Regulation of zooplankton biomass and production in a temperate, coastal ecosystem. 2. Ciliates. Limnol Oceanogr 39:508-519

Ohman MD, Runge JA (1994) Sustained fecundity when phytoplankton resources are in short supply: omnivory by Calanus finmarchicus in the gulf of St Lawrence. Limnol Oceanogr 39:21-36

Osgood KE, Checkley DMJ (1997) Observations of a deep aggregation of Calanus pacificus in the Santa Barbara Basin. Limnol Oceanogr 42:997-1001

Parsons TR, Lalli CM (1988) Comparative oceanic ecology of the plankton communities of the Subarctic Atlantic and

Editorial responsibility: Hans Heinrich Janssen, Oldendorf/Luhe, Germany
Pacific oceans. Oceanogr Mar Biol Annu Rev 26:317-359

Pearre S (2003) Eat and run? The hunger/satiation hypothesis in vertical migration: history, evidence and consequences. Biol Rev Camb Philos Soc 78:1-79

Primicerio R (2003) Size-dependent habitat choice in Daphnia galeata Sars and size-structured interactions among zooplankton in a subarctic lake (lake Lombola, Norway). Aquat Ecol 37:107-122

R Development Core Team (2009) R: A language and environment for statistical computing. R Foundation for Statistical Computing, Vienna. www.R-project.org

Rey-Rassat C, Irigoien X, Harris R, Carlotti F (2002) Energetic cost of gonad development in Calanus finmarchicus and C. helgolandicus. Mar Ecol Prog Ser 238:301-306

Ringelberg J (1995) Changes in light intensity and diel vertical migration: a comparison of marine and freshwater environments. J Mar Biol Assoc UK 75:15-25

Roe H, Angel MV, Badcock J, Domanski P, James P, Pugh P, Thurston $M$ (1984) The diel migrations and distributions within a mesopelagic community in the northeast Atlantic. 1. Introduction and sampling procedures. Prog Oceanogr 13:245-268

Sakshaug E, Bjørge A, Gulliksen B, Loeng H, Mehlum F (eds) (1994) Økosystem Barentshavet. Research Council of Norway, Oslo

Sprules WG, Jin EH, Herman AW, Stockwell JD (1998) Calibration of an optical plankton counter for use in fresh water. Limnol Oceanogr 43:726-733

Stefansky W (1972) Rejecting outliers in factorial designs. Technometrics 14:469-479

Swift JH 1986. The Arctic waters. In: Hurdle G (ed) The Nordic Seas. Springer Verlag, Berlin, p 130-153

Tande KS, Båmstedt U (1985) Grazing rates of the copepods Calanus glacialis and Calanus finmarchicus in Arctic Waters of the Barents Sea. Mar Biol 87:251-258

> Titelman J, Fiksen O (2004) Ontogenetic vertical distribution patterns in small copepods: field obervations and model predictions. Mar Ecol Prog Ser 284:49-63

- Varpe $\varnothing$, Jørgensen C, Tarling GA, Fiksen $\varnothing$ (2009) The adaptive value of energy storage and capital breeding in seasonal environments. Oikos 118:363-370

Wiebe PH, Morton AW, Bradley AM, Backus RH and others (1985) New developments in the MOCNESS, an apparatus for sampling zooplankton and micronekton. Mar Biol 87: $313-323$

Wood S (2004) Stable and efficient multiple smoothing parameter estimation for generalized additive models. J Am Stat Assoc 99:673-686

Wood S (2006) Generalized additive models: an introduction with R. Chapman and Hall/CRC, Boca Raton, FL

Zaret TM, Suffern JS (1976) Vertical migration in zooplankton as a predator avoidance mechanism. Limnol Oceanogr $21: 804-813$

Submitted: April 7, 2010; Accepted: August 2, 2010

Proofs received from author(s): October 4, 2010 